\title{
The hLEF/TCF-1 $\alpha$ HMG protein contains a context-dependent transcriptional activation domain that induces the TCR $\alpha$ enhancer in $T$ cells
}

\author{
Peter Carlsson, ${ }^{1,4}$ Marian L. Waterman, ${ }^{2,4}$ and Katherine A. Jones ${ }^{3}$ \\ The Salk Institute for Biological Studies, La Jolla, California 92037 USA
}

\begin{abstract}
hLEF/TCF-1 $\alpha$ is a lymphoid cell-specific HMG protein that activates the distal enhancer of the gene encoding the $\alpha$-subunit of the T-cell receptor (TCR $\alpha$ ). We have shown previously that transcriptional activation by hLEF is highly dependent on the context of its binding site within the TCR $\alpha$ enhancer. Here, we demonstrate that hLEF contains a potent transcriptional activation domain that is separate from the HMG motif and is preferentially active in $\mathrm{T}$ cells. We find that hLEF/GAL4 fusion proteins can activate a GAL4-substituted TCR $\alpha$ enhancer up to 50-fold in T-cell lines and are as active as GAL4/VP16 in this context. Unlike GAL4/VP16, however, hLEF/GAL4 could not activate heterologous promoters bearing only GAL4 DNA-binding sites. Thus, activation by hLEF/GAL4, like that noted previously for the native hLEF activator, was strongly influenced by the context of its DNA-binding site within the TCR $\alpha$ enhancer. Inspection of enhancer mutants suggests that trans-activation by hLEF/GAL4 is especially dependent on TCF-2, a distinct T-cell-enriched protein that binds to sequences flanking the hLEF-binding site in the enhancer. Analysis of small deletion or clustered amino acid substitution mutants in the hLEF-coding sequences identified a minimal activation region between amino acids 80 and 256 that appears to be bipartite in structure. The hLEF activation domain is not notably acid or glutamine-rich but is proline-rich and includes a motif rich in tyrosine and serine residues. We conclude that sequences outside of the hLEF HMG box mediate cell- and context-specific activation of the TCR $\alpha$ enhancer and may facilitate interactions between hLEF and other T-cell-specific factors recruited to the enhancer.
\end{abstract}

[Key Words: hLEF/TCF-1 $\alpha$ transcription factor; lymphocyte-specific transcription; TCR $\alpha$ enhancer; context-dependent activation]

Received July 15, 1993; revised version accepted September 21, 1993.

Regulated expression of cellular genes frequently depends on enhancer elements that control distal promoters in a precise tissue- or developmental stage-specific manner. Long-range transcriptional activation from downstream enhancers plays an important role in the expression of genes that encode the various components of the T-cell receptor (TCR) complex, which mediates antigen recognition and signal transduction in activated T lymphocytes (Beyers et al. 1992). The polymorphic TCR subunit genes are composed of variable $(V)$, diversity $(D)$, and joining $(/)$ gene segments that rearrange in somatic cells upstream of a constant $(C)$ gene segment. Nearly $100 V \alpha$ and 50-100 J $\alpha$ segments lie within $65 \mathrm{~kb}$ of the various $C \alpha$ exons for the $\alpha$-chain of the human TCR (Satyanarayana et al. 1988), and expression of the

Present addresses: 'Department of Molecular Biology, University of Goteborg, Goteborg, Sweden; ${ }^{2}$ Department of Microbiology and Molecular Genetics, School of Medicine, University of California, Irvine, Irvine, California 92717 USA.

${ }^{3}$ Corresponding author.

${ }^{4}$ These authors contributed equally to this work. rearranged TCR $\alpha$ genes is controlled by a strong T cellspecific enhancer located $4.5 \mathrm{~kb}$ downstream of the most distal $C \alpha$ exon (Ho et al. 1989; Winoto and Baltimore 1989|. The TCR $\alpha$ enhancer may therefore act over a great distance to regulate expression of the rearranged $\alpha$-chain genes in $\mathrm{T}$ lymphocytes.

A short region of the TCR $\alpha$ enhancer that spans $112 \mathrm{bp}$ has been shown to possess potent cell type-specific activity and to be necessary and sufficient for enhancer activity in TCR $\alpha, \beta|+|$ cell lines (Winoto and Baltimore 1989). This minimal enhancer domain contains binding sites for at least three different factors: (1) the ubiquitously distributed (CREB/ATF) proteins (Gonzales et al. 1989 ; (2) the lymphoid-specific LEF-1/TCF- $1 \alpha$ protein (Waterman and Jones 1990; Waterman et al. 1991; Travis et al. 1991); and (3) a T cell-enriched protein called TCF-2 (Waterman and Jones 1990). Mutations that disrupt any of these three protein binding-sites (or greatly alter the spacing between the CREB and LEF-1/TCF-1 $\alpha$ sites) destroy enhancer activity in vivo (Ho et al. 1989; Winoto et al. 1989), suggesting that the enhancer-bound 
proteins may interact in a stereospecific manner with each other or with other proteins bound at the promoter. In contrast, neither single nor multiple copies of the LEF$1 /$ TCF- $1 \alpha$-binding site affected transcription when removed from the CRE and TCF-2-protein binding sites and positioned upstream of heterologous promoters (Waterman and Jones 1990; Travis et al. 1991). Therefore, it seems that LEF-1/TCF-1 $\alpha$ cannot activate transcription on its own, although it can strongly induce the TCR $\alpha$ enhancer when acting in concert with the TCF-2 and CRE-binding proteins.

TCF- $1 \alpha$ was originally identified as a $\mathrm{T}$ cell-specific family of $53-$ to $55-\mathrm{kD}$ DNA-binding proteins that bind specifically to a motif $\left(5^{\prime}\right.$-CCTTTGAA- $\left.3^{\prime}\right)$ present in the minimal TCR $\alpha$ enhancer and the human immunodeficiency virus-1 (HIV-1) enhancer, and transient expression assays revealed that its binding site is essential for TCR $\alpha$ enhancer activity in T cells (Waterman and Jones 1990). Analysis of cDNA clones encoding TCF-1 $\alpha$ revealed a 68-amino-acid DNA-binding domain that is highly conserved among various high mobility group (HMG) proteins (Waterman et al. 1991). Transient expression of TCF-1 $\alpha$ in nonlymphoid cells resulted in a modest induction of the TCR $\alpha$ enhancer, suggesting that the cloned protein is active for transcription. The murine homolog of TCF-1 $\alpha$, called LEF-1 (lymphoid enhancer factor-1), was concomitantly isolated by Grosschedl and colleagues using a subtractive hybridization cloning method (Travis et al. 1991). In addition, a distinct $\mathrm{T}$ cellenriched HMG protein, TCF-1, was cloned by Clevers and colleagues using an expression screening protocol (van de Wetering et al. 1991). The TCF-1 protein is closely related to LEF-1/TCF-1 $\alpha$ within the HMG domain but is otherwise much less related in sequence and is expressed from a different gene. To avoid confusion between TCF-1 $\alpha$ and TCF-1, we will hereafter refer to the human TCF-1 $\alpha$ protein as hLEF (for human LEF), and the murine LEF-1 protein as MLEF. The LEF protein is expressed in pro- and pre-B cells as well as in all T-cell lineages that have been tested, whereas TCF-1 is exclusively detected in T-cell lineages (Travis et al. 1991; Oosterwegel et al. 1993). In situ hybridization experiments have further revealed that both TCF-1 and mLEF are widely expressed early during development and that their patterns of expression partially diverge at later stages of mouse development (Oosterwegel et al. 1993). Postnatal expression patterns of both genes were exclusively restricted to lymphoid cells (Oosterwegel et al. 1993). As suggested by the high degree of similarity within the HMG domain, the TCF-1 and LEF proteins possess similar or identical DNA-binding properties in vitro (Giese et al. 1992); however, it has not been resolved whether the two proteins affect transcription similarly or whether they function as distinct regulatory proteins, as might be expected from their (partially) distinct patterns of expression during development.

Although many characterized HMG proteins have been shown to interact with structured or bent DNA in a relatively sequence-independent manner, a subfamily of regulatory HMG proteins has been identified that act as sequence-specific DNA-binding proteins. These include proteins that contain multiple HMG motifs, such as hUBF, a nucleolar protein that binds to the RNA polymerase I enhancer (Jantzen et al. 1990) and the mitochondrial transcription factor mtTF1 (Fisher et al. 1989; Diffley and Stillman 1992), as well as a different group of proteins that contain only a single HMG motif, including SRY, a mammalian testis-determination protein (Harley et al. 1992); IRE-ABP, an insulin-responsive factor (Nasrin et al. 1991); Ste11, a transcriptional activator of mating-type control genes in yeast (Sugimoto et al. 1990); MatMc, a M-mating-type compatibility factor (Kelly et al. 1988); and T160, a ubiquitously distributed mammalian protein that can bind to the $V-(D)-I$ recombination signal (Shirakata et al. 1991). The LEF-1 and TCF-1 proteins have been shown to bind specifically to a pyrimidine-rich DNA sequence, 5'-CTTTG-3' (Waterman and Jones 1990; Giese et al. 1991; Travis et al. 1991; van der Wetering et al. 1991; Waterman et al. 1991; van der Wetering and Clevers 1992), and SRY, Ste11, and iron response element-activator binding protein (IRE-ABP) have been shown to possess related DNA-binding specificities (Giese et al. 1991; Nasrin et al. 1991; Travis et al. 1991; van de Wetering et al. 1991, 1992; Harley et al. 1992). Most of the DNA contacts made by LEF/TCF-1 and SRY lie within the minor groove (Giese et al. 1991. van de Wetering et al. 1992), which probably contributes to the moderate (50-fold) degree of binding specificity shown for LEF-1 (Giese et al. 1991). The HMGl and HMG2 proteins are able to bend and wrap DNA into tightly compacted forms (Paull et al. 1993; for review, see Lillie 1992). Similarly, the LEF and SRY HMG domains induce dramatic bends in double-stranded helical DNA $\left(130^{\circ}\right.$ and $85^{\circ}$, respectively; Ferrari et al. 1992; Giese et al. 1992), and the SRY HMG box can bind to angled four-way junction DNA in a sequence-nonspecific manner (Ferrari et al. 1992). These findings have interesting implications for the mechanism of TCR $\alpha$ enhancer activation, as bending by LEF could facilitate protein-protein interactions between the otherwise distally located CREB and TCF-2 transcription factors /Giese et al. 1992). As a consequence, the ability of LEF to bind and bend the DNA could explain why its activity is closely connected to the relative location of its binding site within the TCR $\alpha$ enhancer.

These findings raise the question of whether LEF plays only a structural role in enhancer activation that is mediated through bending or wrapping of the DNA, or whether it also contains an activation domain that might interact directly with other transcription factors. We have observed that the cloned hLEF protein modestly enhances expression of the TCR $\alpha$ enhancer in nonlymphoid cells (HeLa or Namalwa B-cell lines; Waterman et al. 1991), and similar results were reported for mLEF (Giese et al. 1991). Our subsequent studies revealed that truncation mutants of hLEF that retain the HMG box but lack sequences at the amino terminus could not activate the TCR $\alpha$ enhancer in Namalwa cells (P. Carlsson, unpubl.). These results suggested that sequences outside of the HMG domain are necessary for activation 
by hLEF. In this report we show that the hLEF protein contains a modular activation domain that is distinct from the HMG box and that hLEF/GAL4 fusion proteins lacking the HMG domain are potent transcriptional activators in $T$ cells. Whereas the hLEF/GAL4 protein strongly activated expression of a construct in which the GAL4 DNA-binding site was positioned between the TCF-2 and CRE sites in the TCR $\alpha$ enhancer, it could not activate other GAL4-containing promoters, indicating that activation by hLEF/GAL 4 is context dependent. Analysis of TCR $\alpha$ enhancer mutants suggests that the hLEF activation domain functions in synergy with TCF2 . The activation domain was defined by in-frame deletion and site-directed substitution mutations and was found to include a hydrophobic motif flanked by a tyrosine- and serine-rich region. We conclude that hLEF regulates the minimal TCR $\alpha$ enhancer in T cells through a strong trans-activation domain that can be separated from the HMG motif.

\section{Results}

Specific binding of hLEF to the TCR $\alpha$ enhancer requires the HMG box as well as an adiacent basic motif

We reported previously that a 162 -amino-acid region of
hLEF that spans the HMG box (amino acids 237-399) is both necessary and sufficient for binding to DNA in vitro (Waterman et al. 1991). Grosschedl and colleagues demonstrated further that a 92-amino-acid synthetic peptide of mLEF (amino acids 287-380; equivalent to amino acids 289-382 of hLEF) or an 88-amino-acid recombinant mLEF protein (amino acids 296-385, equivalent to amino acids 298-387 of hLEF) can bind specifically to the TCR $\alpha$ enhancer (Giese et al. 1991). This region of LEF includes the 68-amino-acid HMG box homology (amino acids 297-364), as well as a 9-amino-acid basic motif (KKKKRKREK) located carboxy-terminal to the HMG box (designated B box in Fig. 1B), that is a potential nuclear localization signal and could also affect binding of LEF to DNA. To delineate sequences further within the HMG domain that affect binding to DNA, we analyzed the properties of different mutant hLEF proteins synthesized in vitro. SDS-PAGE of the ${ }^{35}$ S-labeled translation products established that each of the different hLEF mutants was expressed at levels equivalent to the wild-type protein (Fig. 1A, top). The ability of each protein to bind to the TCR $\alpha$ enhancer was then examined by gel mobility shift experiments (Fig. 1A, bottom), and the results are summarized in Figure 1B. An 83-aminoacid protein (M10; amino acids 297-379) that includes the HMG homology, as well as 6 of the 9 basic amino
A
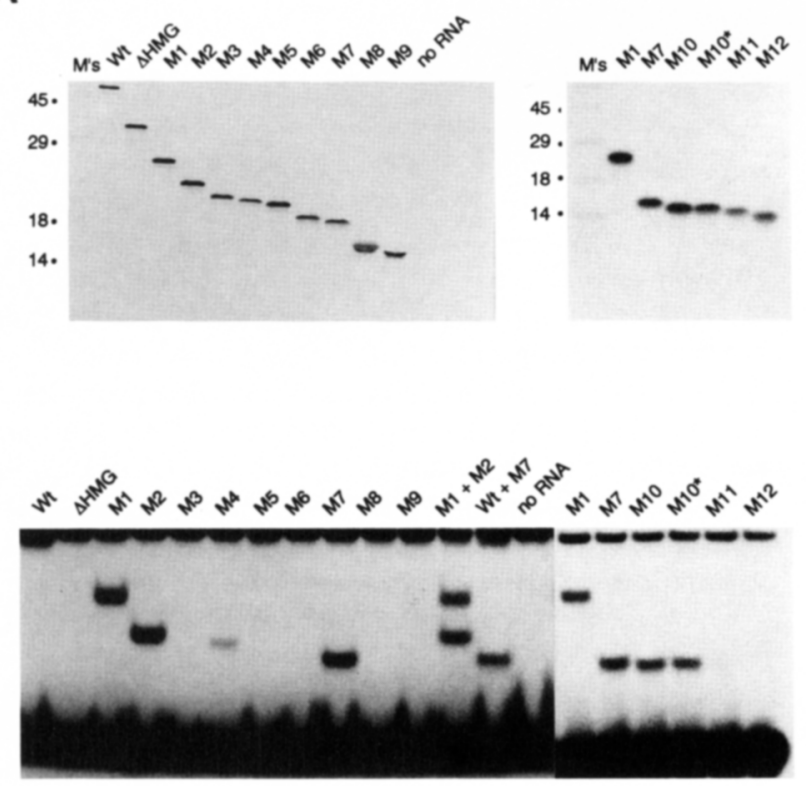

B

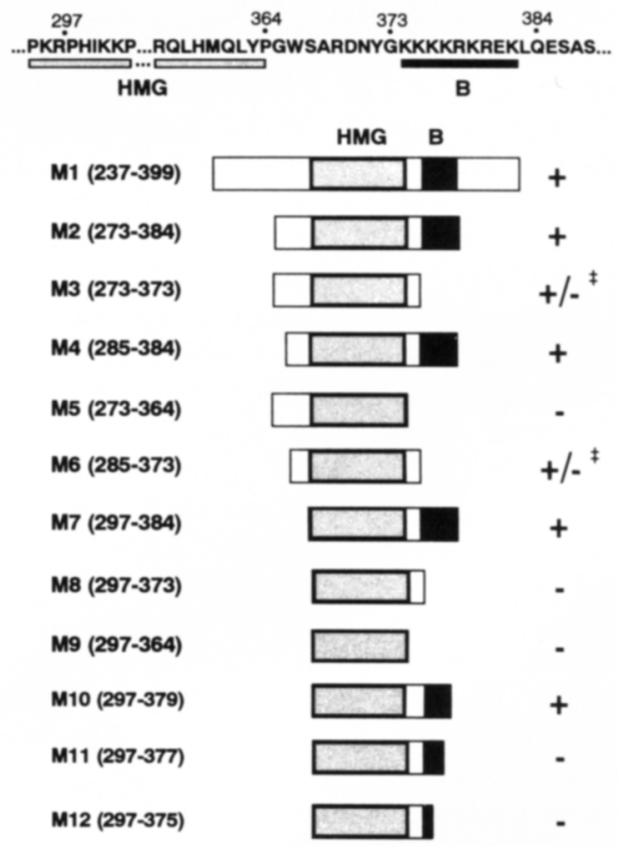

Figure 1. Binding of hLEF requires the HMG box and a downstream basic motif (B box). $(A)$ Full-length, wild-type hLEF and deletion mutants ( $\triangle \mathrm{HMG}$, and $\mathrm{M} 1-\mathrm{M} 12$ ) were synthesized in vitro using reticulocyte lysate extracts. ${ }^{35} \mathrm{~S}$-Labeled proteins were analyzed by SDS-PAGE. M10* is a mutation in which residues Lys-376 and Lys-377 were changed to arginine within the background of the M10 mutation. (no RNA) Control translation reaction without exogenous RNA added. The sizes (in $\mathrm{kD}$ ) of molecular mass markers are indicated. In vitro-translation products were analyzed for binding to the wild-type hLEF site in the TCR $\alpha$ enhancer in a gel mobility shift assay. Full-length hLEF migrates just below a nonspecific shift observed with all translation samples. Combinations of wild-type hLEF with mutant M7, or mutant M1 and mutant M2 RNA, were mixed and cotranslated to assess whether hLEF binds to DNA as a multimer. $(B)$ Summary of the DNA-binding activities of the various mutant hLEF proteins. $¥$ For mutants M3 and M6 refers to proteins that bound weakly but specifically to the TCR $\alpha$ enhancer in DNase I footprinting experiments (data not shown). 
acids of the B box, was the shortest fragment that bound efficiently in the mobility shift assay. Removal of an additional 2 amino acids from the $B$ box eliminated binding of hLEF in vitro (M11; Fig. 1A).

To assess more stringently the ability of the mutant hLEF proteins to contact the TCR $\alpha$ enhancer, several of the mutant proteins were expressed in bacteria and analyzed at higher protein concentrations for binding to the enhancer in DNase I footprint experiments (data not shown). Binding in this assay was determined to be specific, as none of the proteins recognized a mutant site that was shown previously to prevent binding of native hLEF protein (Waterman et al. 1991; data not shown). Mutants M3 (amino acids 273-373) and M6 (amino acids 285-373), which contain the entire HMG homology but lack the basic B box, were capable of specific, albeit weak, binding to the TCR $\alpha$ enhancer in DNase I footprint experiments (data not shown). Thus, the 68-aminoacid HMG homology and proximal carboxy-terminal residues are sufficient to mediate specific binding to DNA, although optimal high affinity binding of hLEF also requires the basic residues in the $B$ box. Further deletion at the carboxy-terminal boundary of the B box to amino acid 364 (M5) abolished binding in the DNase I footprint assay, confirming that the 10 amino acids just downstream of the HMG homology (between amino acids 373 and 364) are critical for binding (data not shown). Thus, the overall charge density of the B box, rather than its amino acid sequence, may determine its influence on DNA-binding affinity. Consistent with this possibility, a mutant protein bearing two Lys $\rightarrow$ Arg substitutions in the B box (mutant M10*, altered at amino acids 376 and $377)$ bound to the TCR $\alpha$ enhancer site as efficiently as a protein that contains the equivalent wild-type sequence (mutant M10; Fig. 1A). We conclude that sequence-specific DNA binding is specified by the HMG box and proximal carboxy-terminal basic motif and that inclusion of at least 6 amino acids from the downstream basic motif ( $B$ box) is required for high affinity binding of hLEF to its specific site.

We also tested whether hLEF binds to DNA as a monomer or multimer by cotranslation of full-length and truncated hLEF proteins and analysis of the resulting protein-DNA complexes in gel mobility shift experiments. No complexes of intermediate mobility were detected upon cotranslation of the full-length hLEF protein with mutant M7 or upon coexpression of mutants M1 and M2, indicating that hLEF binds to DNA as a monomer (Fig. 1A). These latter findings are consistent with the results of Giese et al. (1991) for the binding of mLEF to the TCR $\alpha$ enhancer, as well as our previous conclusions using recombinant hLEF/TCF- $1 \alpha$ proteins (Waterman et al. 1991).

\section{Transcriptional activation by hLEF/GAL4 fusion} proteins in T cells

Transcriptional activation by the RNA polymerase I enhancer factor, hUBF, has been shown to depend on sequences that lie within its multiple HMG domains (Jan- tzen et al. 1992). Thus, activation by hUBF is in some way coupled to the HMG box and could be linked closely to structural distortion of the DNA helix induced by the HMG domain. Similarly, the ability of LEF to bend DNA could play a key role in activating the TCR $\alpha$ enhancer, for example, by facilitating interactions between the CRE and TCF-2 proteins or transcription factors bound to the promoter and enhancer (Giese et al. 1992). The strong context dependence of activation by hLEF could therefore arise as a consequence of DNA bending or wrapping, and if so, residues outside of the HMG homology and $\mathrm{B}$ box might be expected to be dispensable for activation. To determine whether expression of the hLEF HMG DNA-binding domain is sufficient to activate the $\mathrm{TCR} \alpha$ enhancer in vivo, full-length and mutant hLEF proteins were expressed in a mature B-cell line (Namalwa) that lacks endogenous LEF or TCF-1-binding activity (Waterman and Jones 1990). We have shown previously that expression of the full-length hLEF protein in B (Namalwa) or nonlymphoid cells can weakly activate (2.5- to 5-fold) a reporter gene containing the minimal TCR $\alpha$ enhancer upstream of the herpes simplex virus (HSV) thymidine kinase (tk) promoter (Waterman et al. 1991). We found that trans-activation in Namalwa B cells was not affected by removal of 67 amino acids from the amino terminus of hLEF ( $N \Delta 67$ ) but was destroyed by an amino-terminal truncation to position 295, which does not impinge on the hLEF DNA-binding domain (N $\Delta 295$; data not shown). Similarly, we were unable to detect activation of the TCR $\alpha$ enhancer by the distantly related TCF-1 HMG protein in Namalwa cells (P. Carlsson and $\mathrm{K}$. Jones, unpubl.). Because $\mathrm{N} \Delta 295$ does not affect the DNA-binding domain and because the TCF-1 protein is nearly identical to hLEF within the HMG domain and binds to DNA in vitro in a manner indistinguishable from LEF (Giese et al. 1991), these initial results suggested that enhancer activation by hLEF is not solely dependent on its ability to bend DNA and thereby modify the architecture of the enhancer complex.

To determine whether sequences at the amino terminus of hLEF contain an independent modular activation domain that can be functionally dissociated from the HMG motif, we prepared a variety of expression plasmids that fuse the full-length hLEF protein or different subdomains of the protein to the DNA-binding domain of the yeast GAL4 activator (Fig. 2). Fusion to the GAL4 DNA-binding domain allowed us to characterize the putative hLEF activation domain in $T$ cells without interference from the endogeneous LEF and TCF-1 proteins and offered a clear advantage over transfection into $\mathrm{Na}$ malwa (B) cells or nonlymphoid cell lines that lack TCF-2 activity (Waterman and Jones 1990). Because the activity of the native hLEF protein is strongly dependent on the positioning of its binding site within the TCR $\alpha$ enhancer, a reporter construct was prepared in which the hLEF-binding site in the TCR $\alpha$ enhancer was replaced by the GAL4 DNA-binding site. This construct conserved the spacing between the hLEF and TCF-2 protein-binding sites; however because of the difference in size between the hLEF- and GAL4-binding site sequences, the 
Carlsson et al.

Figure 2. hLEF contains a modular transactivation domain. Various regions of the hLEF cDNA were fused in-frame to the DNA-binding domain of the yeast GAL4 activator (amino acids 1-147). The indicated hLEF/GAL4 proteins were expressed by cotransfection with the luciferase reporter gene palGnlLUC, which contains a single copy of the GAL4-substituted TCR $\alpha$ enhancer upstream of the HSV-l tk promoter (top) in Jurkat cells treated with TPA (see Materials and methods). The structure of wild-type hLEF is shown schematically above the fusion constructs. $\mathrm{hLEF}^{*}$ is a naturally occuring splice variant with a 28-amino-acid internal deletion between amino acids 214 and 241 (Waterman et al. 1991).

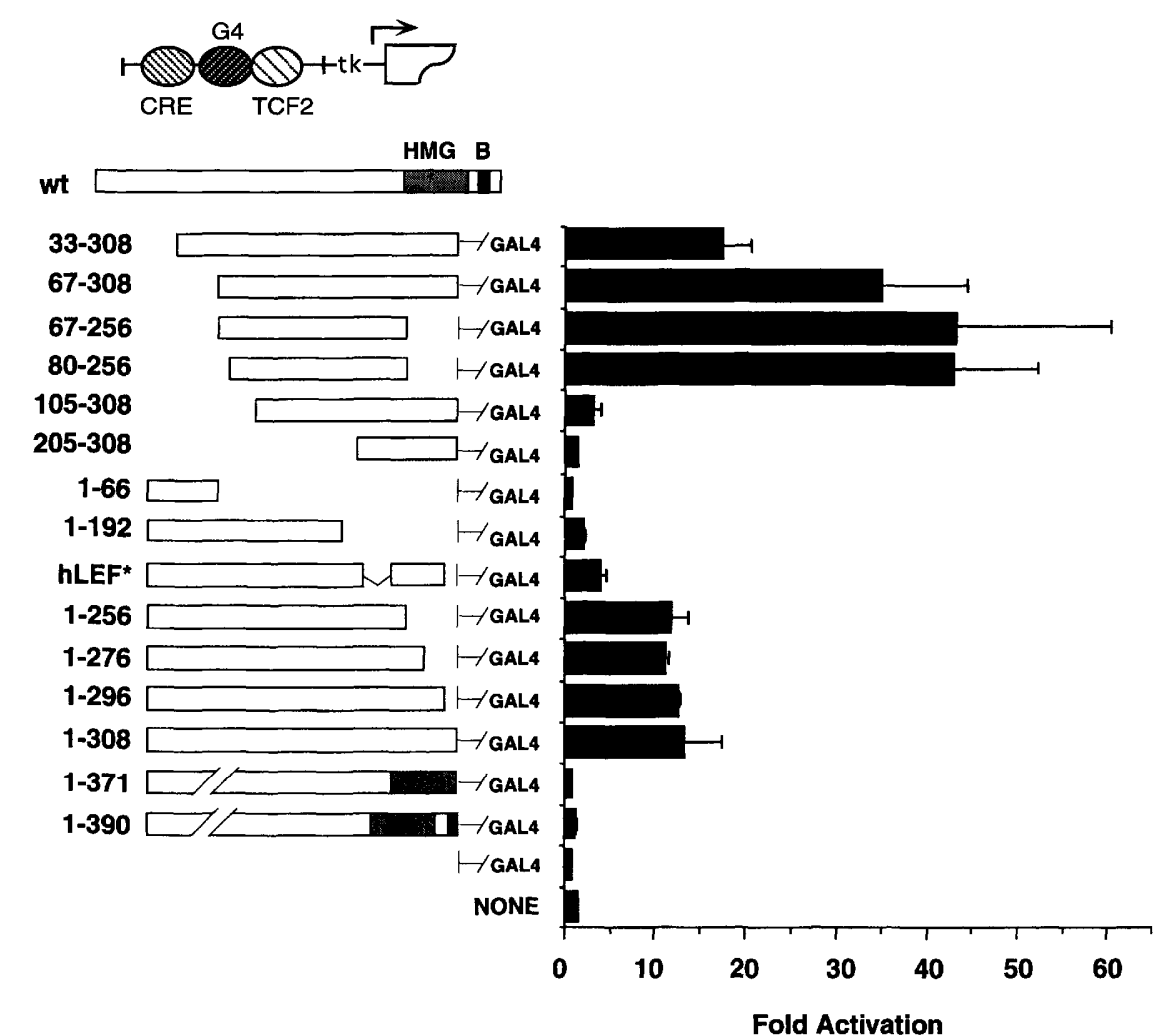

Fold Activation spacing between the CRE element and the GAL4 site was $6 \mathrm{bp}$ closer than that of the native enhancer. Although the spacing between these latter two sites can be important for high levels of enhancer activity (Ho et al. 1990), we have found that a 9-bp deletion between the hLEF and GAL4 sites is well tolerated and supports highlevel enhancer activity when present in tandem copies (M. Waterman., unpubl.). The GAL4-substituted enhancer was found to be strongly induced by various hLEF/GAL4 fusion proteins upon transfection into TPAtreated Jurkat (T) cells [e.g., hLEF(1-308)/GAL4, hLEF(1296)/GAL4, hLEF(1-276)/GAL4, and hLEF(1-256)/ GAL4; Fig. 2]. As has been observed with many other DNA-binding proteins, hLEF/GAL4 fusion proteins that possess two DNA-binding domains (i.e., both the HMG box and the GAL4 DNA-binding domain) were much less active than those that just contain the GAL4-binding domain [hLEF(1-371)/GAL4 or hLEF(1-390)/GAL4; Fig. 2]. During the course of these studies, we also found that constructs containing the GAL4 DNA-binding domain at the amino rather than the carboxyl terminus of hLEF were inactive (e.g., GAL4/hLEF(1-308); data not shown), indicating that the location of the activation domain relative to the DNA-binding domain is very important for hLEF function.

Removal of either 33 or 67 amino acids from the amino terminus of hLEF increased the activation efficiency of the hLEF/GAL4 constructs in T cells [e.g., cf. hLEF(33-308)/GAL4 and hLEF(67-308)/GAL4 with $\mathrm{hLEF}(1-308) / \mathrm{GAL} 4]$, indicating that sequences at the very amino terminus of hLEF are either inhibitory to activity or interfere with protein folding. Further deletion of amino-terminal residues to amino acid 105 [hLEF(105-308//GAL4] largely eliminated trans-activation. Sequential removal of carboxy-terminal residues from amino acids 308 to 296, 276, or 256 did not affect activation, although further deletions to amino acid 192 [hLEF(1-192)/GAL4] or amino acid 66 [hLEF(1-66)/ GAL4] abolished activity (Fig. 2). Taken together, these results suggest that the proximal boundary of the activation domain lies between amino acids 80 and 105 and that the distal boundary is located between amino acids 256 and 192. Interestingly, a naturally occurring variant cDNA (referred to as hLEF ${ }^{\star}$ ) encodes a protein that lacks amino acid residues 214-241, which lie within the distal boundary of the activation domain (Waterman et al. 1991). To determine whether activation by the hLEF* protein was compromised by the loss of these carboxyterminal sequences, we tested the activity of an $\mathrm{hLEF}^{\star} /$ GAL4 fusion protein in this assay [hLEF*(1-296)/GAL4]. As shown in Figure 2, hLEF*/GAL4 was 2.5- to 3-fold less active than the comparable hLEF/GAL4 activator protein [hLEF(1-296)/GAL4]. Therefore, sequences between amino acids 214 and 241 contribute to activation, and the carboxy-terminal boundary of the activation domain may lie somewhere between amino acids 214 and 256. Taken together, the results of this analysis suggest that sequences between amino acids 67 and 256 are necessary for activation. We have confirmed that this region is sufficient for activation of the TCR $\alpha$ enhancer in $\mathrm{T}$ 
cells [hLEF(67-256)/GAL4; Fig. 2], and we subsequently found that the activation domain could be narrowed further at the amino-terminal boundary to amino acid 80 [hLEF(80-256)/GAL4]. Thus, a minimal activation domain of 177 amino acids (amino acids 80-256) is both necessary and sufficient to activate the GAL4-substituted TCR $\alpha$ enhancer in T cells.

\section{Context-dependent activation of the TCR $\alpha$ enhancer by hLEF/GAL4 in T cells}

Importantly, the hLEF/GAL4 protein was as active as the potent GAL4/VP16 activator when assayed on the GAL4-substituted TCR $\alpha$ enhancer in T cells (Fig. 3). In addition, we found that the activity of the hLEF/GAL4 fusion protein was sixfold higher in Jurkat cells than in HeLa cells, indicating that the LEF activation domain is preferentially active in $\mathrm{T}$ cells. The higher activity of hLEF/GAL4 in T cells is likely to be attributed, at least in part, to the fact that the activity of the TCF-2 DNAbinding protein is cell type specific and is not present in HeLa cells (Waterman and Jones 1990). To further assess the relative contribution of TCR $\alpha$ enhancer-binding proteins to trans-activation by hLEF, we tested modified reporter genes that had been deleted of either the CRE or TCF-2 elements. As shown in Figure 3, removal of the CRE motif reduced basal expression greatly and also diminished the level of enhancer activity in the presence of hLEF/GAL4. Nevertheless, hLEF/GAL4 was still able to induce the CRE-deleted enhancer. In contrast, elimination of the TCF-2 protein-binding site not only re- duced basal expression but also destroyed responsiveness of the enhancer to hLEF/GAL4. Consequently, the hLEF activation domain is strikingly dependent on the presence of an intact TCF-2 protein-binding site, and the functional synergy seen between hLEF and TCF- 2 may explain the relatively low level of activation observed with hLEF or hLEF/GAL4 fusion proteins in nonlymphoid cells that lack the TCF- 2 protein.

It has been observed previously that whereas the native LEF protein strongly activates the TCR $\alpha$ enhancer, it is unable to activate heterologous promoters that contain multiple copies of the LEF-binding site (Waterman and Jones 1990; Giese et al. 1991). To learn whether activation by the hLEF/GAL4 fusion protein was similarly restricted to the context of its binding site, we compared the ability of the hLEF/GAL4 and the GAL4/VP16 proteins to induce heterologous GAL4-containing promoters. Interestingly, hLEF/GAL4 could not activate expression from reporter genes carrying five copies of the GAL4-binding site upstream of either the adenovirus ElB or the HSV-1 tk promoter in T cells (Fig. 3). In contrast, these reporters were highly induced by the GAL4/ VP16 activator (Fig. 3; see also Gill et al. 1990). Similarly, a reporter gene carrying six copies of the GAL4binding site upstream of the complete HIV-1 promoter, which is responsive to a GAL4/Tat fusion protein in T cells (Southgate and Green 1991), could not be induced by hLEF/GAL4 (Fig. 3). Thus, the hLEF/GAL4 fusion protein, like the native hLEF protein, cannot function on its own to enhance transcription in T cells. Thus, the hLEF activation domain functions best in $\mathrm{T}$ cells and

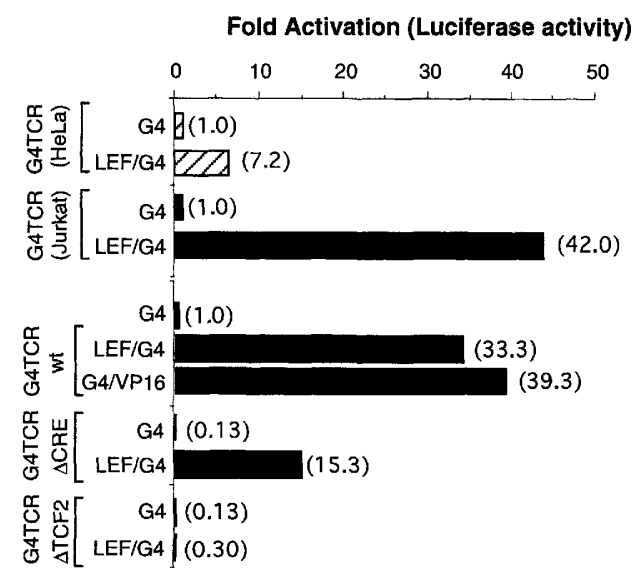

Fold Activation (CAT Activity)

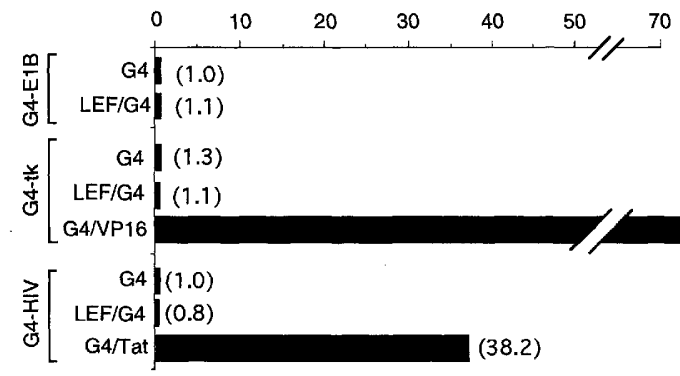

(70.3)

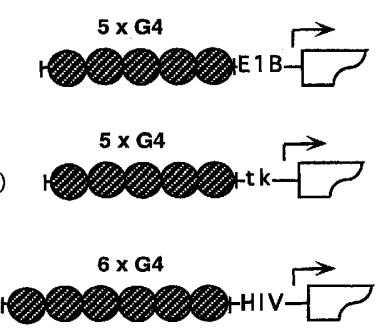

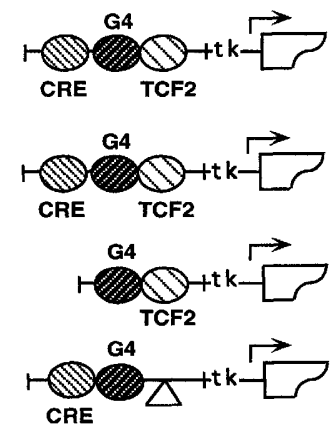

Figure 3. Activation by hLEF/GAL4 is highly context restricted. HeLa and Jurkat cells were transfected with expression vectors encoding either the GAL4 DNA-binding domain [G4, encoding GAL4(1-147)], the hLEF(67-256)/GAL4 fusion protein (LEF/GAL4), the GAL4/VP16 activator (G4/VP16), or the Gal4/Tat chimeric activator (G4/Tat; Southgate and Green 1991). The various reporter genes included palGnlLUC, containing a single copy of the GAL4-substituted TCR $\alpha$ enhancer, a deletion of the CRE motif (pG4 $\triangle \mathrm{CRE}$ ), or a deletion of the TCF2 element (pG4DTCF2), all fused to the tk promoter and luciferase reporter gene. Additional reporter genes tested were pG4E1BCAT, which contains five GAL4-binding sites upstream of the adenovirus E1B minimal promoter, pG4tkCAT, which contains five GAL4binding sites upstream of the HSV-1 tk promoter; or pG6HIVCAT, which contains six copies of the GAL4 site upstream of the Spl-binding sites at -83 in the HIV-1 promoter (Southgate and Green 1991). 
within the context of the TCR $\alpha$ enhancer, even in the absence of an HMG domain and appropriate bending of the enhancer DNA.

\section{Mutational analysis of the hLEF trans-activation domain}

To analyze the hLEF activation domain in greater detail, clustered amino acid substitutions were introduced at 20 -amino acid intervals within the minimal activation region (amino acids 67-256; Fig. 4A,B). These mutations introduced a restriction site that facilitated the construction of additional mutants containing short in-frame deletions that affect large regions of the activation domain. Several single amino acid changes were also created to target-selected histidine, tyrosine, and serine residues clustered within amino acids 84-132 in the amino-terminal half of the activation domain. The mutant genes were fused to the GAL4 DNA-binding domain and evaluated by transfection in TPA-treated Jurkat cells (Fig. 4A), and the results are summarized in Table 1. Singleresidue substitutions affecting His-84, Tyr-102, Tyr-108, Tyr-114, Ser-127, Ser-132, and Ser-200 were found to decrease activation to levels of $31-55 \%$ of that of the wildtype hLEF/GAL4 protein. Among the multiple amino acid changes that most affected activation by hLEF/ GAL4 were mutations clustered between amino acid residues 102-134, including the substitution mutants amino acids 112-114 and 130-134, which reduced activation to $15 \%$ or less of that of the wild-type hLEF/ GAL4 protein. An in-frame deletion mutant affecting this region $(\Delta 112-134)$ also diminished trans-activation in this assay (Fig. 4A). The location of these mutations within the activation domain is summarized in Figure $4 \mathrm{~B}$.

As noted above, the variant hLEF*/GAL4 protein, which contains a 28-amino-acid in-frame deletion affecting residues amino acids 214-241, was less active than the wild-type hLEF/GAL4 fusion protein. We tested two shorter in-frame deletions affecting overlapping sequences within this region and found that each deletion on its own was each less detrimental to activity than the loss of the entire domain $[\Delta(212-227)$ or $\Delta(225-244)$; Fig. 4A]; therefore, the larger deletion present in the hLEF* protein might have affected the conformation or folding of the activation domain. To assess that the hLEF/GAL4 fusion proteins that displayed a mutant phenotype in this assay were expressed and active for binding to DNA, extracts from COS cells transfected with these constructs were prepared and analyzed for binding to the

A
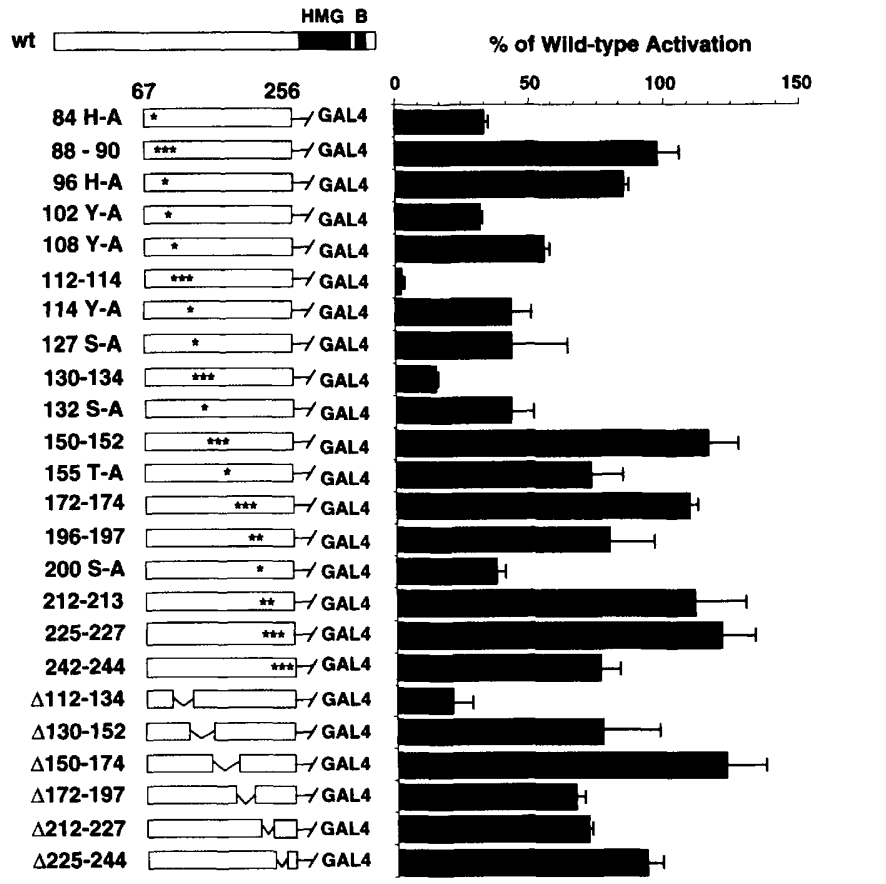

B 91 P D D G K H P D G G L Y N K G P S Y S S Y S G 115 I M M P N M N N D P Y M S N G SL S P P I P R I

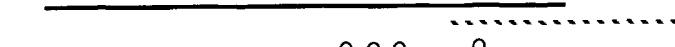
139 S N K V P V V Q P S H A V H P L T P L I T Y S D

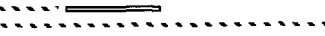
$0-0-0$

163 E H F S P G S H P S H I P D S V N S K Q G M S R

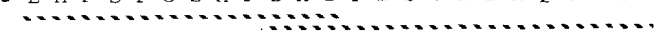
187 H P P A P D I P T F Y P L S G G V G Q I T P P o211 L G W $Q$ G Q P V Y P I T G G F R Q P Y P S S L S $235 \mathrm{~V} D T S M S R$ F S H H M I P G P P G P H T T

Figure 4. Substitution mutagenesis of the minimal hLEF activation domain. (A) Single or clustered mutations that affect 1-3 amino acids in the hLEF activation domain (amino acids 67-256) were fused to the GAL4 DNA-binding domain and tested for trans-activation of the GAL4-substituted TCR $\alpha$ enhancer in Jurkat T cells. NheI sites introduced by the mutations were used to create small internal deletions. The positions of the mutations and deletions are indicated in the diagrams at left. Trans-activation assays were performed in TPA-treated Jurkat cells, and the activity of each construct is reported as a percentage of that of the wild-type hLEF(67-256)GAL4 protein. $(B)$ Sequence of the minimal hLEF/GAL4 activation domain. This summarizes the effects of different mutants on transactivation of the TCR $\alpha$ enhancer by hLEF/GAL4. Shaded circles indicate residues that contribute to activation in T cells; open circles indicate mutations that did not significantly affect enhancer activity. Solid lines denote in-frame deletion mutants that inhibited trans-activation; hatched lines denote deletions that did not reduce trans-activation by hLEF(67-256)/GAL4. 
Table 1. Summary of activation by mutant hLEF/GAL4 proteins in TPA-treated Jurkat cells

\begin{tabular}{lcc}
\hline Mutant & AA replacement & $\begin{array}{c}\text { Relative activity } \\
(\%)\end{array}$ \\
\hline 84 & $\mathrm{H} \rightarrow \mathrm{A}$ & 32.2 \\
$88 / 90$ & $\mathrm{REH} \rightarrow \mathrm{TLA}$ & 95 \\
96 & $\mathrm{H} \rightarrow \mathrm{A}$ & 84.8 \\
102 & $\mathrm{Y} \rightarrow \mathrm{A}$ & 31.5 \\
108 & $\mathrm{Y} \rightarrow \mathrm{A}$ & 55.2 \\
$112 / 114$ & SGY $\rightarrow$ LLA & 2.3 \\
114 & $\mathrm{Y} \rightarrow \mathrm{A}$ & 44 \\
127 & $\mathrm{~S} \rightarrow \mathrm{A}$ & 43 \\
$130 / 134$ & SLSPP $\rightarrow$ LLAPR & 14.9 \\
132 & $\mathrm{~S} \rightarrow \mathrm{A}$ & 44 \\
$150 / 152$ & $\mathrm{AVH} \rightarrow \mathrm{VLA}$ & 115.9 \\
$172 / 174$ & $\mathrm{SHI} \rightarrow$ LLA & 107 \\
$196 / 197$ & FY $\rightarrow$ LA & 6.62 \\
200 & $\mathrm{~S} \rightarrow \mathrm{A}$ & 37.7 \\
$212 / 213$ & GW $\rightarrow$ LA & 110 \\
$225 / 227$ & FRQ $\rightarrow$ LLA & 120.4 \\
$242 / 244$ & FSH $\rightarrow$ LLA & 76.6 \\
$\Delta 112-134$ & & 19.3 \\
$\Delta 130-152$ & & 76.5 \\
$\Delta 150-174$ & & 72.7 \\
$\Delta 172-192$ & & 68 \\
$\Delta 212-227$ & & 71.5 \\
$\Delta 225-244$ & & 91 \\
\hline
\end{tabular}

${ }^{\text {aPercent }}$ of wild-type hLEF (67-256)/GAL4 activity which was normalized to a Rous sarcoma virus (RSV) $\beta$-galactosidase control.

GAL4 DNA site in mobility shift experiments (Fig. 5). Each of the mutant proteins tested bound to GAL4 DNA equivalently, and the mutant proteins were comparably expressed by immunoblot analysis of the COS cell extract (data not shown). Immunoprecipitation analysis of proteins transfected from $\mathrm{T}$ cells indicated further that mutants 112/114, S132-A, S127-A, S200-A, and 130/134 were expressed at levels comparable to the wild-type hLEF(67-256)/GAL4 protein (data not shown). Taken together, our findings suggest that residues near the amino terminus of the hLEF protein, and particularly those between Tyr-102 and Pro-134, are very important for activation of the TCR $\alpha$ enhancer by hLEF in T cells. Analysis of in-frame deletion mutants affecting internal portions of the hLEF activation domain revealed that a 25 amino-acid central region (amino acid 150 and 174) could be removed without affecting activity (Fig. 4A). In addition, loss of an adjacent 23-amino-acid region (amino acids 130-152) resulted in only a modest drop in activity. These data suggest that the activation domain is bipartite in structure and includes a nonessential region that extends, at a minimum, from amino acid 150 to 174 . The apparent domain structure of the hLEF protein defined in this study is shown schematically in Figure 6 and is discussed further below.

\section{Discussion}

Several members of a newly identified class of nuclear regulatory proteins that contain a single HMG domain, including LEF, TCF-1 (van de Wetering et al. 1991), SRY (Harley et al. 1992), MatMc (Kelly et al. 1988), IRE-ABP (Nasrin et al. 1991), and Stell (Sugimoto et al. 1990), have been implicated to play diverse regulatory roles as sequence-specific DNA-binding proteins, although little is known in detail about the roles of these proteins in
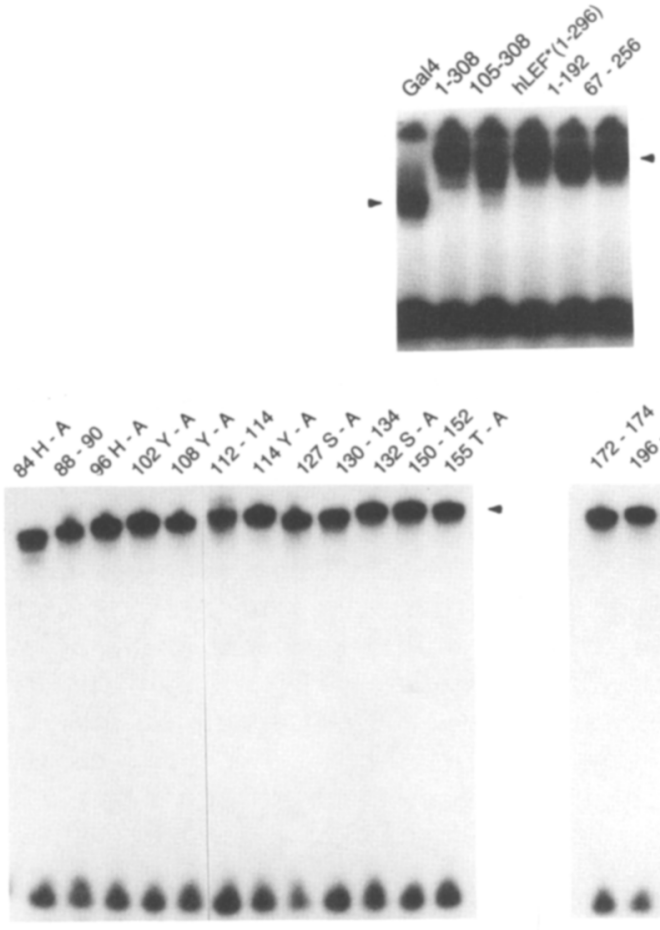
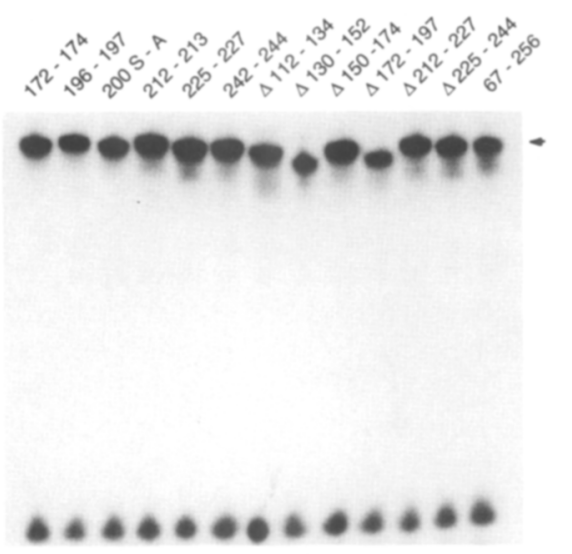

Figure 5. Stable expression of the various hLEF/GAL4 fusion proteins. The DNAbinding activity of selected hLEF/GAL4 fusion proteins is analyzed following transfection into COS-7 cells. Whole-cell extracts were made $48 \mathrm{hr}$ post-transfection and used in a gel shift assay to assess levels of expression of the different mutant proteins and their ability to bind to the GAL4 sequence. Protein expression of each of the mutants was confirmed by immunoblot analysis of the COS cell extracts with antisera to hLEF and to GAL4 /data not shown). The arrowheads indicate specific complexes produced by extract from transfected COS-7 cells. GAL4 refers to a construct expressing only the GAL4 DNAbinding domain. 
Figure 6. Domains of the hLEF HMG protein important for enhancer activation in $T$ cells. Domains of hLEF that affect transactivation by hLEF/GAL4 in T cells are indicated schematically. In-frame deletion mutants were used to define the boundaries of the bipartite activation domain between 150 and 174 or 135 and 174 . Residues at the amino terminus that inhibited activation (amino acids 1-33) are not indicated. Homology between hLEF and mLEF within sequences of trans-activation domain $A$ are indicated in boldface type; note that this region is significantly different in the TCF-1 and CLEF HMG proteins, which may regulate the TCR $\alpha$ enhancer. In addition, a weak homology is observed with certain caudal-like proteins (Frumkin et al.

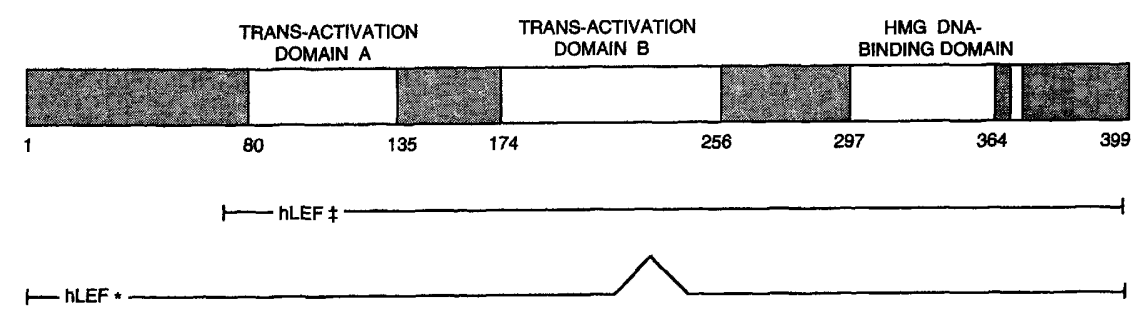
1991), as well as the SRF-associated Ets proteins SAP-1 and Elk-1 (Dalton and Treisman 1992). A potential MAP kinase (Alvarez et al. 1991) phosphorylation site at Ser-132 is boxed.

transcription. Although the LEF and TCF-1 proteins have been found to be widely expressed early in murine embryogenesis (Travis et al. 1991; Oosterwegel et al. 1993), they are expressed exclusively in lymphoid cell lineages in the adult and bind to pyrimidine-rich regulatory elements that are commonly distributed among $\mathrm{T}$ lymphocyte-specific enhancers /Waterman and Jones 1990; Travis et al. 1991; van de Wetering et al. 1991, 1992; Waterman et al. 1991). We and others have shown that the LEF protein activates the minimal TCR $\alpha$ enhancer together with CREB and a distinct $T$ cell-specific protein, TCF-2 (Travis et al. 1991; Waterman et al. 1991). In this paper we demonstrate that high affinity binding of hLEF to DNA is mediated by the HMG box in combination with a stretch of basic residues that lies downstream of the HMG box, and that hLEF/GAL4 fusion proteins that lack this DNA-binding domain are potent activators of a modified TCR $\alpha$ enhancer in which the hLEF-binding site has been replaced with the GAL4 DNA-binding motif. The hLEF activation domain identified in these studies (Figure 6) is preferentially active in $T$ cells, functions in a context-specific manner, and differs in sequence from the well-characterized acid- or Gln-rich domains that have been described for other RNA polymerase II transcription factors (Mitchell and Tijan 1989). Thus, transcriptional activation by hLEF differs fundamentally from that characterized for the hUBF HMG protein, which activates the RNA polymerase I enhancer through sequence elements within the HMG motifs that promote interactions between hUBF and the SL-1 TATA-binding protein (TBP)/TBP-associated factors (TBP/TAF) complex (Jantzen et al. 1992). Instead, sequences upstream of the HMG box, which are highly conserved between hLEF and MLEF, seem to be essential for regulation of the TCR $\alpha$ enhancer.

Among the mutations that most affected trans-activation of the TCR $\alpha$ enhancer by hLEF/GAL4 were clustered substitutions or deletions affecting a tyrosine- and serine-rich sequence (SYSSYSGY) and a flanking hydro- phobic stretch located within activation domain A (Fig. 6). The domain A sequence is highly conserved with the murine LEF-1 protein but is substantially altered in the more distantly related TCF-1 protein and in a chicken LEF-related protein of unknown function (CLEF; Gastrop et al. 1992). There are also significant differences between hLEF and TCF-1 within the remaining region of the activation domain. Because we were unable to detect activation of the TCR $\alpha$ enhancer in B cells by TCF-1 (P. Carlsson, unpubl.|, under conditions where the human and the murine LEF-1 proteins activated transcription (Giese et al. 1991; Waterman et al. 1991), it is likely that the TCF-1 protein does not regulate TCR $\alpha$ enhancer activity in T cells. Because TCF-1 and LEF are nearly identical in the HMG DNA-binding domain and bind similarly or identically to DNA in vitro (Giese et al. 1992), the inability of TCF-1 to influence TCR $\alpha$ enhancer activity is most likely attributable to differences in the activation domain. Thus, LEF and TCF-1 may play different roles in transcription in $T$ cells, depending on their ability to function in specific DNA-binding contexts.

Sequences related to the hLEF activation domain A are also found in two developmentally regulated caudal-like proteins from chicken and zebrafish that may function as transcription factors (Frumkin et al. 1991), as well as a domain of the Ets-related SAP-1 and Elk-1 proteins that mediates binding of these factors to the serum response transcription factor, SRF (Dalton and Treisman 1992; Treisman et al. 1992). Ternary complex formation between SRF and the Elk-1-related protein, p62TCF, is critical for transcriptional activation through the serum response element (SRE) regulatory element and is affected by phosphorylation of p62TCF by the mitogen-activated protein (MAP) kinase (Herrera et al. 1989). The minimal LEF activation domain also contains three potential phosphorylation sites for the MAP kinase (Fig. 4B), and we have found that native LEF is phosphorylated in vivo and that recombinant LEF can be phosphorylated at Ser- 
132 and Ser-200 by MAP and cdc2 kinases in vitro (M. Waterman, unpubl.). However, the phosphorylation pattern of hLEF/GAL4 is more complex in vivo and the identity of the physiological kinases for LEF remain to be established. Thus, the hLEF domain A sequence might form part of a domain that is important for protein-protein interactions between LEF and other factors assembled at the enhancer.

Trans-activation by LEF seems to be tightly associated to the context of its binding site within the enhancer, because an element composed only of reiterated copies of the hLEF-binding site will not activate gene expression in T cells (Waterman and Jones 1990; Travis et al. 1991). Therefore, LEF may function as a transcriptional activator only in conjunction with accessory proteins that bind to flanking regions of the TCR $\alpha$ enhancer. Binding of LEF has been shown to introduce a sharp bend in the DNA that profoundly affects the local structure of the enhancer; consequently, it has been proposed that LEF might play an indirect or "architectural" role in enhancer activation by facilitating interactions between the otherwise distal CRE and TCF-2 proteins (Giese et al. 1992). The studies carried out here indicate that strong context-restricted activation is observed with hLEF fusion proteins containing the yeast GAL4-binding domain, which does not dramatically bend DNA /Carey et al. 1989), and thus sequences outside of the HMG motif are also critical for enhancer activation. It remains possible that the effects of the hLEF activation domain would be even more pronounced if coupled to a DNAbinding domain that is capable of properly bending the enhancer DNA. We attempted to assess the activity of fusion proteins containing hLEF upstream region fused to the Ste11 HMG domain, as the preferred Stell binding site is not recognized with high affinity by LEF /Giese et al. 1992); however, we encountered interference from endogeneous T-lymphocyte factors that apparently are capable of binding the Stel 1 motif (P. Carlsson, unpubl.); thus, this issue remains an open question. We conclude that the role of hLEF in TCR $\alpha$ enhancer activation is not limited to its effects on regional DNA structure but also requires an activation domain that can independently facilitate transcription in a context-dependent manner in $\mathrm{T}$ cells.

To investigate the contribution of adjacent proteinbinding sites to enhancer activation by hLEF, we examined the ability of the hLEF/GAL4 protein to induce constructs lacking either the CRE or the TCF- 2 elements. Although removal of the CRE lowered basal as well as induced levels of enhancer activity, this construct remained highly inducible by the hLEF/GAL4 protein. In contrast, loss of the TCF-2 protein-binding site essentially eliminated activation by hLEF/GAL4. Consequently, hLEF is very dependent on TCF- 2 for TCR $\alpha$ enhancer activation in this assay, and thus the two proteins might interact directly. A direct interaction between these two proteins could explain the observed cell type specificity of the hLEF activation domain, because TCF2-binding activity was seen only in T-cell extracts (Waterman and Jones 1990). Although it has been reported that Ets-1 can bind to the TCF-2 site in the TCR $\alpha$ enhancer (Ho et al. 1990), we find that sequences outside of the Ets-1-binding element are critical for TCF-2 activity (T. Mayall, C. Schar, M. Waterman, and K. Jones, unpubl.). In addition, cotransfection of genes expressing Ets-1 and hLEF did not reconstitute TCR $\alpha$ enhancer activity in HeLa cells (P. Carlsson, unpubl.). Therefore, TCF-2 may be a heterodimer containing Ets and a distinct factor. The hLEF- and TCF-2-binding elements are closely positioned one turn apart on the same face of the DNA helix. Although to date we have not observed cooperative binding between hLEF and TCF- 2 in DNase footprint experiments, it remains possible that LEF stabilizes the binding of TCF-2 to DNA or that the two proteins interact subsequent to binding DNA. If so, parallels may exist between LEF and HMG protein HMG $\mathrm{I}(\mathrm{Y})$, which belongs to a different class of $H M G$ proteins than LEF but nevertheless bends DNA and stabilizes the binding of NF- $\mathrm{KB}$ to the human interferon- $\beta$ enhancer to affect transcription in a context-dependent manner (Thanos and Maniatis 1992).

We have observed some differences between the native and hLEF/GAL4-responsive TCR $\alpha$ enhancers that might be due to differences in the DNA-binding properties of the LEF and LEF/GAL4 proteins or to the inability of the latter to bend DNA. First, the level of activation of a single copy of the GAL4-substituted enhancer by hLEF/ GAL4 was significantly greater than that typically observed for the endogeneous hLEF acting through a single copy of wild-type TCR $\alpha$ enhancer. This difference might be due to the fact that the wild-type TCR $\alpha$ enhancer can bind any of the naturally ocurring variants of hLEF as well as the TCF-1 protein; and, as mentioned above, these are likely to differ in transcription activation potential. Consequently, proteins like hLEF ${ }^{*}$ and TCF-1 may compete with the native hLEF protein to diminish wild-type TCR $\alpha$ enhancer activity. By comparision, the activity of the hLEF/GAL4 protein would appear higher than LEF, as it is not affected by other HMG proteins present in $\mathrm{T}$ cells. Alternatively, the differences observed between the natural and substituted enhancers could reflect the higher DNA-binding affinity of GAL4 $\left\{K_{\mathrm{d}}=2 \times 10^{-11} \mathrm{M}\right.$; Sadowski and Ptashne 1989$)$ relative to hLEF $\left(1 \times 10^{-9} \mathrm{M}\right.$; Giese et al. 1991), as well as the fact that GAL4 binds as a dimer whereas hLEF binds DNA as a monomer. Second, induction of the GAL4-substituted enhancer by hLEF/GAL4 was not improved by multimerization of the enhancer, whereas multiple copies of the minimal wild-type TCR $\alpha$ enhancer function in a highly synergistic fashion in vivo (Waterman and Jones 1990). Thus, bending induced by the hLEF HMG domain could help enhancer-bound proteins interact synergistically on reiterated copies of the TCR $\alpha$ enhancer. By extension, bending could also facilitate protein interactions at sites distal to the enhancer, and the reporter gene systems used here would not be sensitive to any effects of bending on long-range promoter activation from a distal downstream enhancer. To better assess the contribution of DNA bending by the HMG domain to enhancer activity, it will be important to use in vitro transcription sys- 
tems to analyze the effects of the recombinant hLEF protein in a defined environment devoid of LEF, TCF-1, or other competing HMG proteins.

We have recently investigated whether the hLEF activation domain could affect the activity of the native hLEF protein functioning on the wild-type TCR $\alpha$ enhancer. Overexpression of the hLEF/GAL4 protein in Jurkat $T$ cells lead to a 10- to 20 -fold enhancement or "superactivation" of the TCR $\alpha$ enhancer in Jurkat T cells (P. Carlsson, unpubl.). In contrast, overexpression of GAL4/ VP-16 slightly inhibited (or squelched) TCR $\alpha$ enhancer activity. Superactivation by hLEF/GAL4 was found to rey-ire the same general region of the protein as that required for activation and was eliminated by mutation of the hLEF-binding site in the TCR $\alpha$ enhancer. Although superactivation is not observed as commonly as squelching, it has been observed previously for the Spl transcription factor (Pascal and Tiian 1991) and was attributed to a weak propensity of Spl monomers to selfassociate, which serves to increase the effective concentration of the Spl activation domain at the promoter. The observation that the hLEF activation domain can modulate the activity of the native enhancer to which LEF binds and bends DNA appropriately provides independent evidence for the ability of this domain to modulate the activity of the endogeneous LEF protein. By analogy with $\mathrm{Spl}$, superactivation by LEF may contribute to the highly synergistic activation that is observed with multiple copies of the TCR $\alpha$ enhancer (Ho et al 1989; Winoto and Baltimore 1989).

Given the strong context dependence of activation by hLEF, it will be particularly informative to identify other target genes for LEF in $T$ cells. Interestingly, a recent study suggests that the hLEF-binding site in the HIV-1 enhancer may be required for viral replication in peripheral blood lymphocytes and in certain mature T-cell lines (Kim et al. 1993). The defect in the mutant viruses was attributed to a defect in transcription, which is surprising given the relatively modest effect of hLEF-binding site mutations on HIV-1 promoter activity in transient expression assays (Waterman and Jones 1990; Zeichner et al. 1991). Therefore, hLEF may contribute more strongly to the activation of viral promoters that have integrated into genome than to promoters present in unintegrated plasmid DNA. Further studies to dissect the HIV-1 enhancer and confirm the involvement of hLEF in viral transcription could provide an important second example of a functional context for the hLEF HMG protein.

\section{Materials and methods \\ Construction of wild-type and mutant hLEF/GAL4 chimeric activator genes}

HMG subregions indicated in Figure 1 were generated by PCR using oligonucleotide primers beginning or ending at the deletion endpoints indicated in Figure 1. PCR products were subcloned into the SmaI site of Bluescript SK -. Complete open reading frames were sequenced, and correct clones were excised with BamHI and EcoRI for insertion into homologous sites in the bacterial expession vector, pGEMEX (Pharmacia), modified to remove most of bacterial gene 10 -coding sequences $(\mathrm{H}$. Mangalam, pers. comm.) as described further by Waterman and Jones (1990).

Wild-type hLEF protein and mutant derivatives were expressed in the pLysS bacterial strain (Studier et al. 1990) using the modified pGEMEX vector described above. Recombinant proteins were isolated as described previously (Waterman and Jones 1990). Proteins were partially purified by elution from a heparin-agarose column in TM.4M buffer $150 \mathrm{mM}$ Tris at $\mathrm{pH}$ $7.9,12.5 \mathrm{~mm} \mathrm{MgCl} 2,1 \mathrm{~mm}$ EDTA, 20\% glycerol, $400 \mathrm{mM} \mathrm{KCl}$, $1 \mathrm{mM}$ DTT) and, where indicated, further purified to $>90 \%$ homogeneity using FPLC mono $S$ column fractionation and salt gradient elution (20 mM HEPES at $\mathrm{pH} 7.9,50 \mathrm{mM} \mathrm{KCl}$ to $800 \mathrm{mM}$ $\mathrm{KCl}, 10 \%$ glycerol, $1 \mathrm{~mm}$ DTT, $0.2 \mathrm{~mm}$ PMSF, $0.2 \mathrm{mM}$ EDTA| Most of the recombinant hLEF proteins eluted between 250 and $400 \mathrm{mM} \mathrm{KCl}$, and were dialyzed before use.

The luciferase reporter plasmid $\alpha 1$ tk 100 has been described elsewhere (Waterman and Jones 1990). To make the GAL4-substituted variant $\alpha 1 \mathrm{Gn} 1-\mathrm{LUC}$, the hLEF site in the TCR $\alpha$ enhancer of $\alpha 1 \mathrm{tk} 100$ was replaced with the double-stranded oligodeoxynucleotide 5'-AAGAGGGGACGGAGTACTGTCCTCCGAA-3' (the GAL4-binding motif is underlined). The hLEF cDNA (Waterman et al. 1991) was subcloned between BamHI and KpnI sites in the eukaryotic expression vector pEV3S (Matthias et al. 1989) and fused in-frame by insertion of the complementary linkers 5'-GATCCCCCCAACTCT-3' and 5'-CCGGAGAGTTGGGGG-3' between BamHI in the vector and $B s p E I$ in the hLEF-coding sequence. To modify the sequence encoding the GAL4 DNA-binding domain (amino acids 1-147) for insertion downstream of hLEF, plasmid pSG424 (Sadowski et al. 1989) was used as template in a PCR reaction with the primers 5'-CCTCTAGAGCGATACAGTCAACTGTCTTTG$3^{\prime}$ and 5'-CTGGTACCAGATGAAGCTACTGTCTTCTATC$3^{\prime}$. This introduced a KpnI site upstream of the start codon of GAL4 and an $X b a I$ site with a stop codon downstream of codon 147. Insertion of the PCR product between $K p n I$ and $X b a I$ sites in $\mathrm{pEV} 3 \mathrm{~S} / \mathrm{hLEF}$ resulted in plasmid pLEF/GAL4, which was used to create the different fusion constructs. Carboxy-terminal deletions in the hLEF sequence were made using exonuclease III/mung bean nuclease and amino-terminal deletions with Bal31 nuclease. Additional carboxy-terminal deletions ending at amino acids 256, 276, and 296 were created by PCR with KpnI-tagged antisense primers. Single-amino-acid point mutations and three-amino-acid substitutions were made with the three-step-PCR mutagenesis method (Nelson and Long 1989). NheI restriction sites introduced by the three-residue substitution were then used to create internal deletions within the hLEF activation domain. The G4 $\triangle \mathrm{CRE}$ and G4DTCF2 reporter genes were constructed by selective PCR amplification of portions of the core TCR $\alpha$ enhancer from the G4TCR construct. For G4 4 TCF2, the following oligonucleotide primers were used: $5^{\prime}$ TCTCATGTCTGGATCCCTCCC-3' and 5'-GGGGATCCTTCGGAGGACAGTACTC-3'. Digestion of BamHI sites present at either end of the amplified fragment allowed insertion into the BamHI site of the parent vector tklo0LUC (Waterman and Jones 1990). For G4DCRE, the following oligodeoxynucleotides were used: 5'-GGGGATCCGGTTACCAAGAGGGGC-3' and 5'-GCTGTTGACGCTGTTAAGCGGGTC-3'. Digestion with Sau3A separated the enhancer from tk promoter sequences and allowed insertion of the amplified fragment into the BamHI site of the parent vector tk100LUC (Waterman and Jones 1990).

For construction of the 5XG4-tkCAT reporter gene, appropriate oligonucleotides were used to amplify the HSV-1 tk promoter from tk100LUC and following digestion of the fragment 
with $\mathrm{XbaI}$ and $\mathrm{BamHI}$, the amplified fragment was inserted into the parent vector, 5XG4-EIBCAT using the following oligodeoxynucleotides: 5'-GCTCTAGAGGTCCGAGGTCCACTTC$3^{\prime}$ and 5'-CAAGATCTGCGGCACGCTGTTGACG-3'. The 6 XG4-HIV|-83|CAT vector and G4/Tat expression vectors were obtained from Dr. Michael Green (University of Massachusetts Medical Center; Worcester, MA) and have been described previously (Southgate and Green 1991). All constructs were verified by dideoxy sequencing and restriction mapping, and fragments generated by PCR were sequenced in their entirety.

\section{Cell culture, transfections, CAT, and luciferase assays}

Jurkat and Namalwa cells were maintained in RPMI medium, HeLa, and COS-7 cells were grown in DMEM. Both media were supplemented with $10 \%$ fetal calf serum, penicillin, and streptomycin. Cells were transfected by electroporation using $5 \mu \mathrm{g}$ of luciferase reporter plasmid, $10 \mu \mathrm{g}$ of the relevant hLEF expression plasmid, and $2 \mu \mathrm{g}$ of pCMV-CAT as internal reference. When pG5BCAT (Gill et al. 1990) (10 $\mu \mathrm{g}$ ) was used as reporter, $1 \mu \mathrm{g}$ of pRSV-LUC was used as an internal control. Electroporation was performed as described (Carlsson and Bjursell 1989) with a BTX 600 apparatus at $250 \mathrm{~V}$ and $800 \mu \mathrm{F}$ for HeLa, $1000 \mu \mathrm{F}$ for Jurkat, and $1600 \mu \mathrm{F}$ for Namalwa and COS-7 cells. After discharge, cells were plated in $12 \mathrm{ml}$ of medium, with or without $50 \mathrm{ng} / \mathrm{ml}$ of TPA (phorbol 12-myristate 13-acetate, Sigma), and incubated overnight $(\sim 16 \mathrm{hr})$. Luciferase activities were determined as described (Waterman and Jones 1990) and corrected for transfection efficiency variations by normalization to CAT activities determined with the diffusion assay (Neumann et al. 1987; Carlsson and Bjursell 1989). All transfections were done in duplicate and repeated at least twice.

To assess the stability of the various mutant hLEF/GAL4 proteins, COS-7 cells were transfected with hLEF/GAL4 expression plasmids ( $20 \mu \mathrm{g} / 10-\mathrm{cm}$ dish) by electroporation, incubated for $48 \mathrm{hr}$, harvested, and lysed by freeze-thawing in $80 \mu \mathrm{l}$ of $5 \times$ elution buffer (Schmitz and Baeuerle 1991) containing 0.2\% NP40. Binding reactions contained $4 \mu \mathrm{l}$ of cell extract, $1 \mu \mathrm{g}$ of poly[d(I-C)] and $\sim 20,000 \mathrm{cpm}$ of the $5^{\prime}{ }^{\prime 2} \mathrm{P}$-labeled GAL4 DNA oligonucleotide in a $20-\mathrm{ml}$ final reaction volume. Reactions were incubated for $30 \mathrm{~min}$ on ice and resolved on $0.25 \times \mathrm{TBE}$ PAGE at $4^{\circ} \mathrm{C}$.

In vitro expression of mutant hLEF proteins and mobility shift experiments

Wild-type and mutant derivatives of hLEF were cloned into a modified pGEMEX vector (Pharmacia, see above) under control of the T7 promoter. Five micrograms of each plasmid was linearized with HindIII and transcribed with $\mathrm{T} 7$ polymerase as described previously (Waterman et al. 1991). RNA was translated by a rabbit reticulocyte lysate (Promega) supplemented with $2.5 \mu \mathrm{l}(37.5 \mu \mathrm{Ci})$ of $\left[{ }^{35} \mathrm{~S} \mid-\right.$-methionine. The programmed reticulocyte lysate $(0.1-0.2 \mu \mathrm{l})$ was analyzed by SDS-PAGE, and $1 \mu l$ was tested for DNA-binding activity in gel mobility shift experiments.

For the binding assays, the in vitro-synthesized hLEF proteins were incubated with $1 \mu \mathrm{g}$ of poly $[\mathrm{d}(\mathrm{I}-\mathrm{C})]$ in a $14-\mu \mathrm{l}$ reaction $(10$ $\mathrm{mM}$ HEPES-KOH at $\mathrm{pH} 7.8,2.4 \mathrm{mM}$ EDTA, $5 \mathrm{~mm}$ spermidine, $10 \%$ glycerol, $1 \mathrm{mM}$ DTT, $0.5 \mathrm{~mm}$ PMSF, and $100 \mathrm{~mm} \mathrm{KCl}$ ) for $10 \mathrm{~min}$ on ice. The ${ }^{32} \mathrm{P}$-labeled oligodeoxynucleotide DNA probe $(0.2-0.5 \mathrm{ng} ; 1 \mu \mathrm{l})$ was added, and the incubation continued for an additional $10 \mathrm{~min}$ at room temperature. Reactions were resolved on an $0.25 \times \mathrm{TBE} / 6 \%$ native polyacrylamide gel as de- scribed previously (Waterman et al. 1991). The sequence of the wild-type TCR $\alpha$ enhancer oligodeoxynucleotide probe was $5^{\prime}$ GATCTAGGGCACCCTTTGAAGCTCT-3'.

\section{Acknowledgments}

We thank Dr. Michael Green for the GAL4/Tat and G4HIVCAT vectors, Dr. Ian Sadowski for the antisera to the GAL4 DNAbinding domain, Tim Mayall for assistance with some of the transfections, Keith Cannon for DNA binding and Western blots, Jian-Ping Liu for tissue culture, and Christine Schar for technical assistance. This study was funded by the National Institutes of Health (grant PO1 CA54418 and the Mathers Foundation). P.C. was supported by a fellowship from the Swedish Medical and Natural Sciences Research Councils; M.L.W. is a fellow of the Leukemia Society; and K.J. is a PEW scholar in the Biomedical sciences.

The publication costs of this article were defrayed in part by payment of page charges. This article must therefore be hereby marked "advertisement" in accordance with 18 USC section 1734 solely to indicate this fact.

\section{References}

Alvarez, E., I. Northwood, G. Gonzalez, D. Latour, A. Seth, C. Abate, T. Curran, and R. Davis. 1991. Pro-Leu-Ser/Thr-Pro is a consensus primary sequence for substrate protein phosphorylation. I. Biol. Chem. 266: 15277-15285.

Beyers, A., L. Spruyt, and A. Williams. 1992. Multimolecular associations of the T-cell antigen receptor. Trends Cell Biol. 2: 253-255.

Carey, M., H. Kakidani, J. Leatherwood, F. Mostashari, and M. Ptashne. 1989. An amino-terminal fragment of GAL4 binds DNA as a dimer. J. Mol. Biol. 209: 423-432.

Carlsson, P. and G. Bjursell. 1989. Negative and positive promoter elements contribute to tissue specificity of apolipoprotein B expression. Gene 77: 113-121.

Dalton, S. and R. Treisman. 1992. Characterization of SAP-1, a protein recruited by serum response factor to the $\mathrm{c}$-fos serum response element. Cell 68: 597-612.

Diffley, J.F.X. and B. Stillman. 1992. DNA binding properties of an HMG1-related protein from yeast mitochondria. J. Biol. Chem. 267: 3368-3374.

Ferrari, S., V. Harley, A. Pontiggia, P. Goodfellow, R. LovellBadge, and M. Bianchi. 1992. SRY, like HMGl, recognizes sharp angles in DNA. EMBO 7 . 11: 4497-4506.

Fisher, R.P., M.A. Parisi, and D.A. Clayton. 1989. Flexible recognition of rapidly evolving promoter sequences by mitochondrial transcription factor 1. Genes \& Dev. 3: 22022217.

Frumkin, A., Z. Rangini, A. Ben-Yehuda, Y. Gruenbaum, and A. Fainsod. 1991. A chicken caudal homologue, Chox-cad, is expressed in the epiblast with posterior localization and in the early endodermal lineage. Development 112: 207-219.

Gastrop, J., R. Hoevenagel, J.R. Young, and H.C. Clevers. 1992. A common ancestor of the mammalian transcription factors TCF- 1 and TCF- $1 \alpha /$ LEF- 1 expressed in chicken T cells. Eur. J. Immunol. 22: 1327-1330.

Giese, K., A. Amsterdam, and R. Grosschedl. 1991. DNA-binding properties of the HMG domain of the lymphoid-specific transcriptional regulator LEF-1. Genes \& Dev. 5: 2567-2578.

Giese, K., J. Cox, and R. Grosschedl. 1992. The HMG domain of lymphoid enhancer factor 1 bends DNA and facilitates assembly of functional nucleoprotein structures. Cell 69: 185196. 
Gill, G., I. Sadowski, and M. Ptashne. 1990. Mutations that increase the activity of a transcriptional activator in yeast and mammalian cells. Proc. Natl. Acad. Sci. 87: 2127-2131.

Gonzalez, G.A., U.K. Yamamoto, W.H. Fischer, D. Karr, P. Menzel, W. Biggs, W.W. Vale, and M.R. Montminy. 1989. A cluster of phosphorylation sites on the cyclic AMP-regulated nuclear factor CREB predicted by its sequence. Nature 337: 749-752.

Harley, V., D. Jackson, P. Hextall, J. Hawkins, G. Berkovitz, S. Sockanathan, R. Lovell-Badge, and P. Goodfellow. 1992. DNA binding activity of recombinant SRY from normal males and XY females. Science 255: 453-456.

Herrera, R., P. Shaw, and A. Nordheim. 1989. Occupation of the c-fos serum response element in vivo by a multi-protein complex is unaltered by growth factor induction. Nature 340: $68-70$.

Ho, I.-C., L.-H. Yang, G. Morle, and J. Leiden. 1989. A T cellspecific transcriptional enhancer element $3^{\prime}$ of $\mathrm{C} \alpha$ in the human T-cell receptor a locus. Proc. Natl. Acad. Sci. 86: 6714-6718.

Ho, I.C., N.K. Bhat, L.R. Gottschalk, T. Lindsten, C.B. Thompson, T.S. Papas, and J.M. Leiden. 1990. Sequence-specific binding of human Ets- 1 to the $T$ cell receptor alpha gene enhancer. Science 250: 814-818.

Jantzen, H.-M., A. Admon, S. Bell, and R. Tjian. 1990. Nucleolar transcription factor hUBF contains a DNA-binding motif with homology to HMG proteins. Nature 344: 830-836.

Jantzen, H.-M., A.M. Chow, D.S. King, and R. Tjian. 1992. Multiple domains of the RNA polymerase I activator hUBF interact with the TATA-binding protein complex hSLl to mediate transcription. Genes \& Dev. 6: 1950-1963.

Kelly, M., M. Burke, A. Smith, A. Klar, and D. Beach. 1988. Four mating-type genes control sexual differentiation in the fission yeast. $E M B O H .7:$ 1537-1547.

Kim, J., F. Gonzales-Scarano, S. Zeichner, and J. Alwine. 1993. Replication of type 1 human immunodeficiency viruses containing linker substitution mutations in the -201 to -130 region of the long terminal repeat. J. Virol. 67: 1658-1662.

Lilley, D.M.J. 1992. HMG has DNA wrapped up. Nature 357: 282-283.

Matthias, P., M. Müller, E. Schreiber, S. Rusconi, and W. Schaffner. 1989. Eukaryotic expression vectors for the analysis of mutant proteins. Nucleic Acids Res. 17: 6418.

Mitchell, P.J. and R. Tjian. 1989. Transcriptional regulation in mammalian cells by sequence-specific DNA binding proteins. Science 245: 371-378.

Nasrin, N., C. Buggs, X. Kong, J. Carnazza, M. Goebl, and M. Alexander-Bridges. 1991. DNA-binding properties of the product of the testis-determining gene and a related protein. Nature 354: 317-320.

Nelson, R. and G. Long. 1989. A general method of site-specific mutagenesis using a modification of the Thermus aquaticus polymerase chain reaction. Anal. Biochem. 180: 147-151.

Neumann, J., C. Morency, and K. Russian. 1987. A novel rapid assay for chloramphenicol acetyltransferase gene expression. BioTechniques 5: 444-447.

Oosterwegel, M., M. van der Wetering, J. Timmerman, A. Kruisbeek, O. Destree, F. Meijlink, and H. Clevers. 1993. Differential expression of the HMG box factors TCF-1 and LEF-1 during murine embryogenesis. Development 118: 439-448.

Pascal, E. and R. Tjian. 1991. Different activation domains of $\mathrm{Sp} 1$ govern formation of multimers and mediate transcriptional synergism. Genes \& Dev. 5: 1646-1656.

Paull, T.T., M.J. Haykinson, and R.C. Johnson. 1993. The nonspecific DNA-binding and -bending proteins HMG1 and HMG promote the assembly of complex nucleoprotein structures. Genes \& Dev. 7: 1521-1534.

Sadowski, I. and M. Ptashne. 1989. A vector for expressing GAL4(1-147) fusions in mammalian cells. Nucleic Acids Res. 17: 7539.

Satyanarayana, K., S. Hata, P. Devlin, M. Grazia Roncarolo, J. De Vries, H. Spits, J. Strominger, and M. Krangel. 1988. Genomic organization of the human $\mathrm{T}$-cell antigen-receptor $\alpha / \delta$ locus. Proc. Natl. Acad. Sci. 85: 8166-8170.

Schmitz, M. and P. Baeuerle. 1991. The p65 subunit is responsible for the strong transcription activating potential of NFкB. $E M B O$ I. 10: 3805-3817.

Shirakata, M., K. Huppi, S. Usuda, K. Okazaki, K. Yoshida, and H. Sakano. 1991. HMG1-related DNA-binding protein isolated with V-(D)-J recombination signal probes. Mol. Cell. Biol. 11: 4528-4536.

Southgate, C. and M. Green. 1991. The HIV-1 Tat protein activates transcription from an upstream DNA-binding site: Implications for Tat function. Genes \& Dev. 5: 2496-2507.

Studier, F., A. Rosenberg, J. Dunn, and J. Dubendorff. 1990. Use of T7 RNA polymerase to direct expression of cloned genes. Methods Enzymol. 185: 60-89.

Sugimoto, A., Y. Iino, T. Maeda, Y. Watanabe, and M. Yamamoto. 1990. Schizosaccharomyces pombe stel1+ encodes a transcription factor with an HMG motif that is a critical regulator of sexual development. Genes \& Dev. 5: 1990-1999.

Thanos, D. and T. Maniatis. 1992. The high mobility group protein $\mathrm{HMG} \mathrm{I}(\mathrm{Y})$ is required for NF-kB-dependent virus induction of the human IFN-B gene. Cell 71: 777-789.

Travis, A., A. Amsterdam, C. Belanger, and R. Grosschedl. 1991. LEF-1, a gene encoding a lymphoid-specific protein with an HMG domain, regulates T-cell receptor alpha enhancer function. Genes \& Dev. 5: 880-894.

Treisman, R., R. Marais, and J. Wynne. 1992. Spatial flexibility in ternary complexes between SRF and its accessory proteins. $E M B O$ I. 11: $4631-4640$.

van de Wetering, $M$. and $H$. Clevers. 1992. Sequence-specific interaction of the HMG box proteins TCF-1 and SRY occurs within the minor groove of a Watson-Crick double helix. EMBO I. 11: 3039-3044.

van de Wetering, M., M. Oosterwegel, D. Dooijes, and H. Clevers. 1991. Identification and cloning of TCF-1, a T lymphocyte specific transcription factor containing a sequence-specific HMG box. EMBO $T$. 10: 123-132.

Waterman, M. and K. Jones. 1990. Purification of TCF- $1 \alpha$, a $\mathrm{T}$-cell-specific transcription factor that activates the $\mathrm{T}$-cell receptor $\mathrm{C} \alpha$ gene enhancer in a context-dependent manner. New Biol. 2: 621-636.

Waterman, M.L., W.H. Fischer, and K.A. Jones. 1991. A thymusspecific member of the HMG protein family regulates the human T cell receptor $\mathrm{C} \alpha$ enhancer. Genes \& Dev. 5: 656669.

Winoto, A. and D. Baltimore. 1989. A novel, inducible and T cell-specific enhancer located at the $3^{\prime}$ end of the $T$ cell receptor $\alpha$ locus. EMBO J. 8: 729-733.

Zeichner, S., J. Kim, and J. Alwine. 1991. Linker-scanning mutational analysis of the transcriptional activity of the human immunodeficiency virus type 1 long terminal repeat. J. Virol. 65: $2436-2444$. 


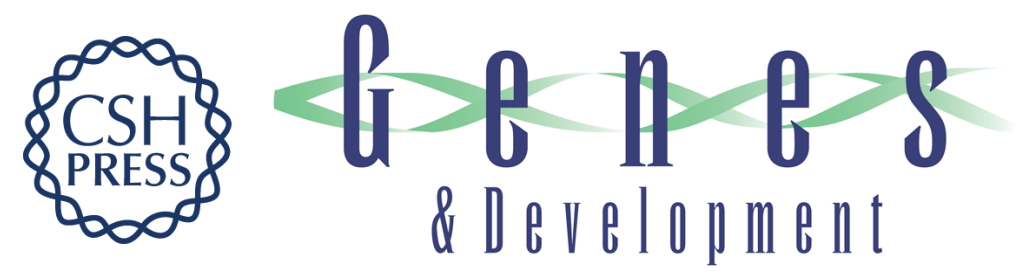

\section{The hLEF/TCF-1 alpha HMG protein contains a context-dependent transcriptional activation domain that induces the TCR alpha enhancer in T cells.}

$\mathrm{P}$ Carlsson, M L Waterman and $\mathrm{K}$ A Jones

Genes Dev. 1993, 7:

Access the most recent version at doi:10.1101/gad.7.12a.2418

\section{References This article cites 47 articles, 21 of which can be accessed free at: http://genesdev.cshlp.org/content/7/12a/2418.full.html\#ref-list-1}

\section{License}
Email Alerting Receive free email alerts when new articles cite this article - sign up in the box at the top Service right corner of the article or click here.

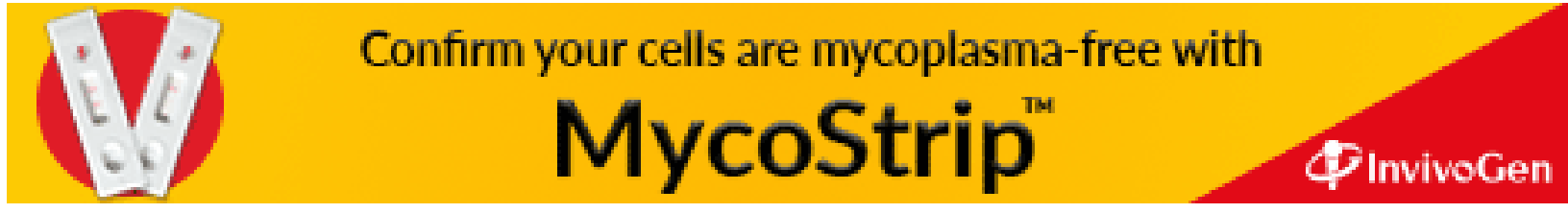

